\title{
Web Service Composition Based On Directed Weight Graph And Services Matching Degree
}

\author{
Xin Luo \\ School of Management \\ Tianjin University \\ Tianjin, China \\ College of Computer Science \& Information Engineering \\ Tianjin University of Science \& Technology \\ Tianjin, China \\ e-mail:njjlx@sina.com
}

\begin{abstract}
In recent years, web service composition provides a new solution to the comprehensive application. During the web services composition, directed graph provides credible choice for the composition process. At the same time, the web service matching degree is an important parameter during the composition. It selects the service which needed in the composition more precisely and improves the quality of web services composition.
\end{abstract}

Keywords-web service composition; QoS (Quality of Service); directed weight graph; matching degree

\section{INTRODUCTION}

With the development of network technology and the need of new composite applications, in the current new application and system business requirement environment, with an open web service manner, which service quality assurance of web service composition is becoming a hot spot of research fields related to Web services.

W3C gave a definition about web service in the Web Service Architecture [1] in 2004: web service is a software system; it is designed to support interoperable interaction between machines on the network. It has a clear, machine-readable description, general standards (Web Services Description Language, WSDL). Other system interact with it by pattern in the description, the specific use of SOAP (Simple Object Access Protocol) messages and other Web standards, with a completely open, loose coupling, standard protocol specification and highly inheritable capabilities Characteristics etc.

Which are the hot topics that has a good extendibility, scalability, and openness of the Web service composition of general formal description method, QoS guarantee and evaluation of web service composition, the use of MDA (Model Driven Architecture) [2] thoughts to guide service composition and so on.

The introduction of QoS for users to choose the high quality of atomic services provide guarantee [3], but there is no guarantee that the results of the service composite must be credible. Zeng etc. with the introduction of QoS model and linear programming technique [4] focused on paying attention to service in the service portfolio choice, puts forward a quality driven approach to service portfolio to choose the appropriate service. Reference [5] realized the service composition with the multi-dimension QoS attributes as constraint mechanism model. Literature [6] designed a controller to derive the web services' trust level according to the atomic web service's different trust types, which provided the execution path for service requester to choose the optimal method.

\section{THE RESEARCH STATUS}

Which the web service itself has the characteristics of loose coupling make a dynamic service combination possible at runtime. Web services has the functional and non-functional attribute, the latter mainly refers to the quality of service (quality of service, QoS) parameters, such as the service time, the cost, accessibility and service reliability, etc. [4,7].

Reference[8] calculated the QoS of dynamic combination of service using the analytic hierarchy process (AHP), the method choose the QoS factor according to the service consumer expectations, calculate the quality of the Web service by use of QoS weight values.

About web service QoS, in theory, literature [9] proposed web service scheduling based on the QoS trust relationship, and reference [10] proposed a web service selection model that supports QoS, both are focused on web services selection choice based on QoS index, but there is no reliable QoS computation method. QCMA proposed by reference [11] is a kind of selection model about service quality perception to customer as the center. Literature [12] in web services selection process was not only considered service providers' objectively QoS information, and reference the service consumer "subjective idea", so that customers can select the appropriate web service from his own point of view. Literature [13] in the web service composition modeling added Petri nets and the workflow components to further optimize the business processes, implements validation to business process based on QoS.

Some studies focus on consistency problem in the communication service data model, it solves based on grammar. In the QoS of service composition [14-17], a lot of research on the formalized description, measure, and put forward QoS model supporting service composition. They solve and optimize QoS constraints problem by linear programming method.

QoS-Aware web service composition based on probability 
realizes the QoS requirement that were difficult to process in traditional methods. The Rollout algorithm probability resolved QoS model that difficult to apply in dynamic service composition [18].

In the literature [19], it defined two kinds of quality parameters of semantic Web service, general parameters and field parameters of web service quality. General parameters are field independence, it refers to has nothing to do with the Web services features of performance indicators, are: time, cost, reliability, security, availability, credibility, etc. The parameters with field related reflect the information about specific area business content, the business context and service providers, etc. To multi-objective optimization problems, for the unified operation, each index needs dimensionless processing i.e. normalized [20].

Service development thought based on SOA put forward a kind of service composition method based on QoS [21], and provides the strategy that can build web service based on QoS and select the best service. It uses the integration of a single service in order to get the whole best quality of the final composite service. It meets the function demand of users' composition service; in the same time, it meets the QoS demand, realized optimization of demand service.

Service research based on QoS [22] can be roughly divided into two categories: One is the service selection of multiple QoS constrained being modeled for the 0-1 knapsack problems or the optimal path problem of directed acyclic graph, provided services selection algorithm based on this model, such as literatures [17,23-25], etc.; Another kind of method establishes QoS ontology, which uses ontology description ability and inference ability to improve the accuracy of service matching, such as the literature [26-28], etc. Web service selection based on QoS can provide users' better quality of service and web service selection based on user demand for QoS and vagueness of the preferences is one of the ways [29].

In this paper, on the basis of previous studies, using directed weight figure, considers common web service QoS properties and matching degree of each web service in the combination to help comprehensive consideration to choose the Web service path.

\section{A DEFINITION To A WeIGHTEd GRAPH}

Set directed graph $\mathrm{G}=(\mathrm{V}, \mathrm{E})$, the vertex $\mathrm{V}$ represents the Web service. Directed edge between two vertices E represents output of the previous service which can meet input of the latter service, this is to say, two services can be combined. Each vertex has weight attributes that web service itself owned, such as node Vi has a weight of (Vi1, Vi2...)

Each Web service has the service price $(\mathrm{M})$, response time $(\mathrm{T})$, reliability (A) and credibility (R) attributes such as shown in table I:

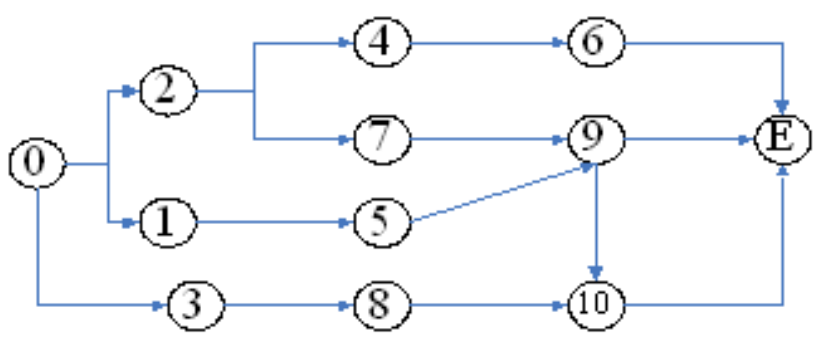

Figure 1. Web service composition diagram

TABLE I. Qos Value of Each Web Service

\begin{tabular}{|l|l|l|l|l||l|l|l|l|l|}
\hline Web & M & T & A & R & Web & M & T & A & R \\
\hline W0 & 120 & 100 & 0.96 & 0.93 & W6 & 130 & 90 & 0.87 & 0.86 \\
\hline W1 & 110 & 105 & 0.94 & 0.94 & W7 & 95 & 125 & 0.94 & 0.96 \\
\hline W2 & 105 & 90 & 0.88 & 0.90 & W8 & 100 & 120 & 0.95 & 0.93 \\
\hline W3 & 90 & 110 & 0.90 & 0.92 & W9 & 125 & 100 & 0.91 & 0.95 \\
\hline W4 & 125 & 120 & 0.86 & 0.88 & W10 & 120 & 130 & 0.89 & 0.91 \\
\hline W5 & 115 & 95 & 0.92 & 0.89 & WE & 110 & 105 & 0.93 & 0.90 \\
\hline
\end{tabular}

The combination according to QoS, chose the path of combination which increases the matching degree as requirement. According to the description logic thoughts, in the process of service composition, required matching service is not completely consistent with the service that can provide input.

A directed edge existed between the vertex $\mathrm{Vi}$ and $\mathrm{Vj}$, there is an order $\langle\mathrm{Vi}, \mathrm{Vj}\rangle$, considering whether the output of the $\mathrm{Vi}$ match exactly with input of the $\mathrm{Vj}$. if it is an exact match, the matching degree is defined as 1 ; If it is completely match defined as a value between 0 and 1 , temporary not consider partial matches, fuzzy matching and plug-in matching.

Suppose listed service in the figure, matching degree that can matched between two services (that is, each edge has a weight) as shown in table II.

TABLE II. MATCHING DEGREE BETWEEN SERVICES SHOWED IN THE FIGURE1

\begin{tabular}{|l|l|l|l|l|l|l|l|l|l|l|l|l|}
\hline & 0 & 1 & 2 & 3 & 4 & 5 & 6 & 7 & 8 & 9 & 10 & $\mathrm{E}$ \\
\hline 0 & & 1 & 0.95 & 0.85 & & & & & & & & \\
\hline 1 & & & & & & 1 & & & & & & \\
\hline 2 & & & & & 0.6 & & & 0.7 & & & & \\
\hline 3 & & & & & & & & & 0.8 & & & \\
\hline 4 & & & & & & & 0.9 & & & & & \\
\hline 5 & & & & & & & & & & 0.6 & & \\
\hline 6 & & & & & & & & & & & & 0. \\
\hline 7 & & & & & & & & & & 0.8 & & \\
\hline 8 & & & & & & & & & & & 0.7 & \\
\hline 9 & & & & & & & & & & & 0.85 & 0. \\
\hline 10 & & & & & & & & & & & & 0. \\
\hline
\end{tabular}




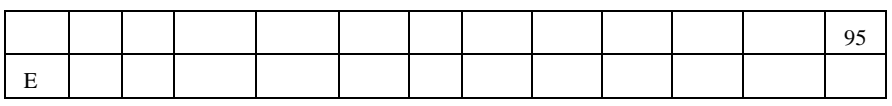

\section{COMPOSITION STRATEGY}

\section{A. Property Normalization}

According to the each attribute characteristics of Web services, some attributes is the less, the better, such as response time, service price etc. some attributes value is the greater, the better, such as reliability etc...In order to unify the incommensurable problem of the attribute in the calculation, use the following as the process method to dispose the response time, service price etc.., with 1 minus all attributes which divided by the maximum number of this attribute value in the all service, as to participate in the calculation of attribute values, which is $1-$ Vin/Vimax, namely take all attributes maximum in the process of composition.. As to the price attribute, the price attribute of the service which participate in the composition respectively is $(60,120,80,110$, 100 ), according to the above method resulting from the conversion $(1 / 6,0.5,0,1 / 3,1 / 12)$ it reflects web service cost's advantage in the web service composition.

The normalized QoS values of the each web service in the composition diagram (Fig.1) are shown in table III.

TABLE III. NORMALIZED QOS VALUES OF THE EACH WEB SERVICE

\begin{tabular}{|l|l|l|l|l||l|l|l|l|l|}
\hline & M & T & A & R & & M & T & A & R \\
\hline W0 & 0.08 & 0.23 & 0.96 & 0.93 & W6 & 0 & 0.31 & 0.87 & 0.86 \\
\hline W1 & 0.15 & 0.19 & 0.94 & 0.94 & W7 & 0.27 & 0.04 & 0.94 & 0.96 \\
\hline W2 & 0.19 & 0.31 & 0.88 & 0.90 & W8 & 0.23 & 0.08 & 0.95 & 0.93 \\
\hline W3 & 0.31 & 0.15 & 0.90 & 0.92 & W9 & 0.04 & 0.23 & 0.91 & 0.95 \\
\hline W4 & 0.04 & 0.08 & 0.86 & 0.88 & W10 & 0.08 & 0 & 0.89 & 0.91 \\
\hline W5 & 0.16 & 0.27 & 0.92 & 0.89 & WE & 0.15 & 0.19 & 0.93 & 0.90 \\
\hline
\end{tabular}

Choosing the possible composition path, that is, from initial vertex to the finish, calculate comprehensive QoS value. Users can select according to his requirements.

According to figure 1 , it has the following composition paths:

Composition path 1: $0,1,5,9, \mathrm{E}$

Composition path 2: $0,2,4,6, \mathrm{E}$

Composition path 3: $0,2,7,9,10, \mathrm{E}$

Composition path 4: $0,3,8,10, \mathrm{E}$

\section{B. Composition Process Calculation}

In the process of service composition, price, response time attributes is calculated by the accumulation, reliability, credibility by multiplication calculation. Considering the matching degree of each compute, it calculates by multiplication as a whole.

The selectivity in the process of composition is: $\sum W_{M, T, A, R} * \prod_{i} S$

As

$$
W_{M}=\sum_{i} V_{i 1} \quad, \quad W_{T}=\sum_{i} V_{i 2} \quad ; \quad W_{A}=\prod_{i} V_{i 3} \quad
$$

$W_{R}=\prod_{i} V_{i 4}, \mathrm{i}$ is the number of the web service which join in the composition.

Each attribute and the match degree of web services in the composition path 1:

Price is: $\mathrm{WM}=\mathrm{V} 01+\mathrm{V} 11+\mathrm{V} 51+\mathrm{V} 91+\mathrm{VE} 1=0.58$

Response time is: $\mathrm{WT}=\mathrm{V} 02+\mathrm{V} 12+\mathrm{V} 52+\mathrm{V} 92+\mathrm{VE} 2=1.11$

Reliability is: $\mathrm{WA}=\mathrm{V} 03 * \mathrm{~V} 13 * \mathrm{~V} 53 * \mathrm{~V} 93 * \mathrm{VE} 3=0.70$

Credibility is: WR=V04*V14*V54*V94*VE4=0.64

$$
\text { Considering the match degree }
$$

$(\mathrm{WM}+\mathrm{WT}+\mathrm{WA}+\mathrm{WR}) * \mathrm{~S} 01 * \mathrm{~S} 15 * \mathrm{~S} 59 * \mathrm{~S} 9 \mathrm{E}=1.55$

The selectivity of the web service composition to the path1 is 1.55 .

The same method: Path2: 1.27; path3:1.31; path4: 1.28

Through the calculation, path1 is the selection of the web service composition.

\section{Contrast Calculation}

Or it focuses on matching degree to composition; every path is calculated separately by formula and the paragraphs path value addition composition:

$$
\sum_{i, j}\left[\left(V_{i 1}+V_{i 2}+V_{j 1}+V_{j 2}\right)+V_{i 3} \times V_{j 3}+V_{i 4} \times V_{j 4}\right] \times S_{i j}
$$

The vertex $i, j$ is the serial number of the web service composition, and tow adjacent services in the path. As Path1, $\mathrm{i}$, $\mathrm{j}$ values followed by $\{(0,1)(1,5)(5,9),(9, \mathrm{E})\}$

The composition selectivity is calculated by the method respectively: 8.29,7.42,9.99,7.47.

Considered in the above four paths, path1, 2, 4 have five services involved in composition, and the path3 has 6 service to participate in, so when using the second method to calculate numerical bigger must be happen, and relative to the path 1 , path3 increase the number of the interface because of more web services in the composition.

In the weight calculation, it adds the interface number to the path, and then the path of the 1,2,3,4 optional were 2.073, $1.855,1.998,1.868$.

Comprehensive consideration, path1 is the preferred composition.

In short, which integrated considering the QoS attributes and matching degree between, path1 is the optimal choice.

\section{SUMMARY}

Web services composition method based on directed weight graph not only considers the function requirement in the combination process, but also at same time, according to the needs of users focus on considering the non-functional requirements. Especially which the combination of the matching degree and QoS attribute, focus on the problem that encountered in the actual web service, and better provide reference path for the users in the process of Web service composition. In the later study, it emphatically pays attention to improve the matching degree between Web services, will be able to better and more precise meet the users' requirements.

\section{REFERENCES}

[1] Web Services Architecture. 2004. http: //www. w3. org/TR /2004 / NOTE-ws-arch-20040211/. 
[2] Model Driven Architecture. http://www.omg.org/mda/.

[3] Xiao Wen, ZHANG Zi-li, LI Wei-hua. Trustworthy Web Service Composition Approach Based on QoS. Computer Science, 2011,38(6):173-176.

[4] ZengLZ, BenatallahB, DumasM, et al. Quality-driven Web Services Composition.//Proceedings of the 12th International Conference on World Wide Web. New York: ACM, 2003:411-421.

[5] Feng X Z, Ren Y, Wu J Q, et al. A Model for Services Composition with Multiple QoS Constraints.//Proceedings of the International Conference on Computing: Theory and Applications Table of Contents.2007:208-213.

[6] Kim Y, Doh K G.A Trust Type Based Model for Managing QoS in Web Services Composition.//Proceedings of the 2007 International Conference on Convergence Information Technology. Washington: IEEE Computer Society, 2007:38-443.

[7] Cardoso J,Sheth A,Miller J,et al. Quality of service for workflows and Web service processes.. Journal of Web Semantics,2004,1(3):281-308.

[8] ZHANG Qi, HOU Hong. Research on Quality of Service Computing Method in Web Service Dynamic Composition. Computer Engineering,2011,37(6):41-43.

[9] HU chun-hua, Wu Min, LIU Guo-ping. QoS Scheduling Based on Trust Relationship in Web Service Workflow. CHINESE JOURNAL OF COMPUTERS , 2009,32(1):42-53

[10] GONG Xiao-yong, ZHU Qing-sheng. Research and Implementation of QoS-aware Model for Web Service Selection. Computer Engineering, 2008, 34(24):55-57.

[11] Lin Weili, Lo Chichun, Chao Kuoming, et al. Multi-group QoS Consensus for Web Services. Journal of Computer and System Sciences, 2010, 77(2): 223-243

[12] Wang Hei-Chia, Lee Chang-Shing, Ho Tsung-Hsien. Combining Subjective and Objective QoS Factors for Personalized Web Service Selection. Expert Systems with Applications, 2007,32(2): 571-584.

[13] Xianfei Tang, Changjun Jiang, Mengchu Zhou. Automatic Web service composition based on horn clauses and Petri nets. Expert Systems with Applications 38(2011):13024-13031.

[14] JIN Hai, CHEN Han-hua, LU Zhi-peng, NING Xiao-min. QoS Optimizing Model and Solving for Composite Service in CGSP Manager. CHINESE JOURNAL OF COMPUTERS, 2005, 28(04): 578-588.

[15] YANG Sheng-wen, SHI Mei-lin. A Model for Web Discovery with QoS constraints. CHINESE JOURNAL OF COMPUTERS, 2005 ,
28(04):589-594.

[16] LIAO Yuan, TANG Lei, LI Ming-shu. A Method of QoS-Aware Service Components Composition. CHINESE JOURNAL OF COMPUTERS, 2005, (04):627-634.

[17] Zeng Liangzhao, Benatallah Boualem, Ngu Anne H.H., et al. QoS-a ware middleware for Web services composition. IEEE Transaction on Software Engineering 2004, 2004,30(5):311.

[18] FENG Ming-zheng. REVIEW OF WEB SERVICS COMPOSITION. Computer Applications and Software,2007,24(2):24-27.

[19] WU Jin-hong, YIN Zhi-ming, WANG Cui-bo. An OWL-S Based Framework for Quality of Semantic Web Service. JOURNAL OF INFORMATION ,2007,26(10).

[20] MAO Yi-mei, LE Jia-jin. RESEARCH ON GENETIC ALGORITHM BASED WEB SERVICE COMPOSITION OPTIMIZATION. Computer Applications and Software, 2008,25(11):199-201,277.

[21] CAO Li-pei, LIU Jing, MIAO Huai-kou. Study on Optimization of Web Service Composition Based on Graph. Computer Science, 2007,34(2):95-99.

[22] ZHU Hong-kang, YU Xue-li. Research on recommendation of Web services based on QoS execution information. Computer Engineering and Applications, 2010,46(18):237-239.

[23] Yu T,Zhang Y,Lin K J. Efficient algorithms for Web services selection with end -to -end QoS constraints. ACM Transactions on Web, 2007, 1(1):6-32.

[24] Dai Y,Yang L,Zhang B,et al. QoS for composite Web services and optimizing. Chinese Journal of Computers, 2006, 29(7):1167-1178.

[25] Canfora G, Dipenta M, Esposito R. An approach for QoS-aware service composition based on generic algorithms. //Proceeding of the 2005 Conference on Genetic and Evolutionary Computation, Washington, 2005:1069-1075

[26] Papaioannou I V. A QoS ontology language for Web -services. //20th International Conference on Advanced Information Networking and Applications (AINA'06), 2006.

[27] Qian M A.A semantic QoS -aware discovery framework for Web services. //2008 IEEE International Conference on Web Services, 2008.

[28] Kritikos K, Plexousakis D. Semantic QoS metric matching. //4 ${ }^{\text {th }}$ IEEE European Conference on Web Services(ECOWS'06), 2006.

[29] SHI Rong-rong,ZHOU Xiao-ming,GUO Cheng-hao. Web service selection fuzzy algorithm for QoS and user's requirements. Application Research of Computers, 2011,28(5):1748-1751. 